\title{
Self-care practices and associated factors among diabetes patients attending the outpatient department in Bahir Dar, Northwest Ethiopia
}

\author{
Teshager Weldegiorgis Abate ${ }^{1 *}$, Minale Tareke ${ }^{2}$ and Mulat Tirfie ${ }^{3}$
}

\begin{abstract}
Objective: The aim of this study was to assess diabetes self-care practice and associated factors among diabetes patients attending Felege-Hiwot Referral Hospital, Bahir Dar, Northwest Ethiopia.

Result: Prevalence of desirable self-care behaviors toward Diabetes Mellitus was $28.4 \%$ (95\% Cl 24.0-32.7\%). There were significant association between the combined treatment modality of tablet with insulin (AOR: $2.72 ; 95 \% \mathrm{Cl}$ 1.01, 7.40), primary and secondary education level (AOR: 4.82; 95\% Cl 1.88, 12.35 and AOR: 3.08; 95\% Cl 1.26, 7.53, respectively). A considerable number of the patients had poor self-care practice, especially lack of social support and treatment modality, which have critical roles in controlling diabetes. Therefore, attention should be given to improve self-care practice.
\end{abstract}

Keywords: Self-care, Diabetes mellitus, Factors, Adult diabetes patient

\section{Introduction}

Diabetes mellitus (DM) is a metabolic diseases characterized by hyperglycemia. It is a defect in insulin secretion, insulin action, or both [1]. DM is a global emergency: one death occurred every six seconds; one limb lost every $20 \mathrm{~s}$ [2]. More than 21 million people have DM in Africa and it will double by 2035 . In Ethiopia, the expected number of diabetes was $>2.135$ million [3]. DM was a cause of admission and boost disease-related complications [4]. Uncontrolled DM causes 2-4 times heart attacks, 2-6 times strokes, and 10-15 years shortens lifespan [5].

The goal of DM care is good metabolic control and render complications by the participation of health care professionals and client themselves [6, 7]. It required adequate self-care practices to keep the disease under control [8]. Self-care is self-limited, voluntary, and outside professional $[9,10]$. In the previous studies, what was

\footnotetext{
*Correspondence: teshagerhylemarriam@gmail.com

${ }^{1}$ Nursing Department, College of Medicine and Health Sciences, Bahir Dar University, P.O.BOX:79, Bahir Dar, Ethiopia

Full list of author information is available at the end of the article
}

documented, high proportion of good practice of regular exercise (60\%); planned dietary regimen (76\%), taking medications $(88.4 \%)[11,12]$. There was a poor self-care practice reported in the previous studies: poor regular exercising, regularly inspected and provided feet care [13-16].

Factors that redder self-care practice in DM patients were being male, housewife [17, 18], married, belonging to higher socioeconomic status, educational status [15-17, 19]; treatment modality [20, 21]. From all of the above review, studies available in the study area were limited in addressing factors that influence self-care practice. Therefore, this study aimed to assess self-care practices and associated factors among diabetes patients.

\section{Main text \\ Methods}

Institution-based cross sectional study was conducted from January 1st to April 8th, 2017 at FHRH. Currently, FHRH has provided promotive, preventive, curative and rehabilitative services. The service was rendered by 
physician and nurses. Patients with DM were visited the hospital on every 2 month basis. The sample size was determined by assuming 5\% marginal error, $95 \% \mathrm{CI}$ and $45 \%$ proportion of DM self-care practice [16]. The final sample size including 10\% non-response rate become 418 DM patients. All diabetes patients aged $\geq 18$ years and who have been on regular follow for DM were included in this study.

Patients' records were listed in follow up appointment order and used as a sampling frame. Then, Systematic random sampling was employed to select eligible participants. Based on the decision to collect data over the course of 1 month, sampling interval was determined by dividing the expected number of diabetic patients per month into the sample size which gives a sampling interval of three. Thus, every three-patient coming to a followup service was interviewed until the total sample size was then reached.

Trained four B.Sc. nurses collected data through face to-face interview and medical chart review. The questionnaire contains socio-demographic, economic, social support [22] and clinical factors. Clinical related factors like diabetes complication was gathered objectively by using checklists. Self-care practice patient with DM was evaluated by self-reported 18-item Summary of Diabetes Self-Care Activities (SDSCA) [23]. SDSCA scale measured frequency of self-care activity in the last 7 days; specifically general and specific diet, physical activity, blood glucose testing, foot care and medication. SDSCA was calculated by summing of the mean score for each dimension divided by the sum of the number of questions under each scale. After calculating an overall mean score, it was classified as having desirable self-care if scored $\geq 3$ or not desirable self-care if scored $<3$.

Structured questionnaire was prepared in English and translated into Amharic, then to check the consistency of the tool the Amharic version translated into English. The questionnaire was carefully evaluated and pretested on $5 \%$ of the sample size in patients with DM at Debretabor Hospital prior to actual data collection. The collected data entered into EPI-data version 3.1 and analyzed using SPSS version 20. Household wealth index was determined by using principal component analysis. The association was investigated by logistic regression. Variables with $\mathrm{P}$-value $<0.2$ in bi-variable analysis were selected for multivariable analysis. Finally, 95\% CI and AOR were presented and interpreted.

\section{Results}

Out of 418, 416 participants were interviewed making the response rate $99.5 \%$. Of all participants 250 (60.1\%) were married and $109(26.2 \%)$ were farmers. The mean age (SD) of the respondents was $41.10 \pm 15.65$ years with minimum age 18 and maximum age 83 (Table 1 ).

\section{Clinical and psychosocial characteristics}

The mean duration (SD) of diabetes treatment was $6.28 \pm 4.87$ years. Eighty-eight participants $(21.2 \%)$ had diabetes retinopathy, which evidenced by a review of patients' charts, and 209 (50.2\%) had poor social support (Table 2).

The overall prevalence of desirable self-care toward DM was $28.4 \%$ (95\% CI 24.0-32.7\%). DM patients who were taking a tablet combined with insulin had more likely to have a good self-care practice when compared to those other treatment regimes. Patients who were primary level education (AOR: 4.82; 95\% CI 1.88, 12.35), widowed (AOR: 4.05; 95\% CI 1.41, 11.58), and who have taken pill other medication (AOR: 2.87; 95\% CI 1.43, 5.76) were more likely to have a good self-care practice. Whereas patients who were housewives (AOR: 0.34; 95\%

Table 1 Socio-demographic characteristics of participant at FHRH, Bahir Dar, Northwest Ethiopia, $2017(n=416)$

\begin{tabular}{|c|c|c|c|}
\hline Variables & Category & Frequency & Percent \\
\hline \multirow[t]{2}{*}{ Sex } & Male & 240 & 57.5 \\
\hline & Female & 176 & 42.3 \\
\hline \multirow[t]{4}{*}{ Age } & $18-34$ & 160 & 38.5 \\
\hline & $35-44$ & 73 & 17.5 \\
\hline & $45-54$ & 87 & 21.9 \\
\hline & $\geq 55$ & 96 & 23.1 \\
\hline \multirow[t]{2}{*}{ Residency } & Urban & 173 & 41.6 \\
\hline & Rural & 243 & 58.4 \\
\hline \multirow[t]{4}{*}{ Marital status } & Single & 123 & 29.6 \\
\hline & Married & 250 & 60.1 \\
\hline & Divorced & 28 & 6.7 \\
\hline & Widowed & 15 & 3.6 \\
\hline \multirow[t]{5}{*}{ Educational status } & Can't read and write & 133 & 32.0 \\
\hline & Read and write & 70 & 16.8 \\
\hline & Primary school (1-8) & 72 & 17.3 \\
\hline & Secondary school (9-12) & 55 & 13.2 \\
\hline & College/University & 86 & 20.7 \\
\hline \multirow[t]{6}{*}{ Occupational } & Farmer & 109 & 26.2 \\
\hline & Civil servant & 92 & 22.1 \\
\hline & Private worker & 52 & 12.5 \\
\hline & Merchant & 76 & 18.3 \\
\hline & House wife & 59 & 14.2 \\
\hline & Others & 28 & 6.7 \\
\hline \multirow[t]{5}{*}{ Income } & Very poor & 83 & 20.0 \\
\hline & Poor & 83 & 20.0 \\
\hline & Middle & 84 & 20.2 \\
\hline & Rich & 83 & 20.0 \\
\hline & Very rich & 83 & 20.0 \\
\hline
\end{tabular}


Table 2 Clinical and psychosocial characteristics of participant at FHRH, Northwest Ethiopia, $2017(n=416)$

\begin{tabular}{lcc}
\hline Variables & Frequency & Percent \\
\hline Types of diabetes mellitus & 242 & \\
Type 2 & 174 & 58.2 \\
Type 1 & & 41.8 \\
Treatment modality & 32 & 7.7 \\
Oral hypoglycemic with insulin & 117 & 28.1 \\
Only oral hypoglycemic & 266 & 63.9 \\
Only insulin & 6 & 1.3 \\
Only diet & & \\
Duration of DM (years) & 291 & 70.0 \\
$\leq 8$ & 107 & 25.7 \\
9-16 & 18 & 4.3 \\
$\geq 17$ & & \\
Taking another medication & 75 & 18.0 \\
Yes & 341 & 82.0 \\
No & & \\
DM complication & 88 & 21.2 \\
Diabetes retinopathy & 52 & 12.5 \\
Diabetes neuropathy & 52 & 12.5 \\
Sexual dysfunction & 70 & 16.8 \\
Foot ulcer & & \\
Social support & 209 & 50.2 \\
Poor & 138 & 32.2 \\
Moderate & 69.6 \\
Strong & & \\
\hline
\end{tabular}

CI $0.13,0.89$ ) and who had poor social support (AOR: $0.29 ; 95 \%$ CI $0.15,0.59)$ were more likely to have a poor self-care practice (Table 3 ).

\section{Discussion}

In this study, good self-care practice among diabetes patients was $28.4 \%$ (95\% CI: $24.0-32.7 \%$ ) towards DM self-care practice in all domains. This level of good selfcare practice was much lower than what has been documented in India, Harari, Addis Ababa and Iran [12, 16, $19,20]$. This might be due to a small sample size and difference setting used by the other study. The study conducted in India was small a sample size, whereas in our study relatively large; in Addis Ababa public hospital was a large sample size, whereas in our study smaller. It is much better when compared to what has been documented in other studies of India and Addis Ababa [18, 21].

In our study, those who under tablet combined with insulin therapy were 2.72 (95\% CI 1.01, 7.40) more likely to have good self-care practice than those who were treated with other treatment modality. A contrasting result were found a study done in Iran 3.6 (95\% CI 2.1,
5.7) and in Addis Ababa 1.94 (95\% CI 1.31, 2.87) for those who under insulin treatment modality $[19,20]$. Comparatively better self-care score among tablet with a combined of insulin therapy in the present study could be these people might have a diabetes which was uncontrolled by mono-therapy (tablets or insulin alone). The combined of insulin with a tablet therapy has complementary mechanisms of action [24, 25].

Social support was found to be significantly associated with good self-care practice. Similar findings were observed in a study done in Jimma [16], Addis Ababa [19] which showed that social support is important to ensure good self-care practice to the multiple diabetes related tasks among DM patients. Perhaps this might be due to effective social support may need to act as a more gentle guiding force that might be motivated behavioral change for the better self-care practice.

Our finding showed that income was one factor that affects self-care behavior in in diabetes patient. This result corresponds with the study finding in Harari [15], which observed a lower to good self-care practice among participants. This may be due to patients might be riskier life style with respect to income due to monetary condition, less accessibility and affordability of recommended self-care practice.

Our finding showed that participants who had formal education reported desirable self-care practice. This result corresponds to the study documented in Harari [15], Jimma [16] and Urban [20]. This might be a participant who had formal education might be escalated their base line information for self-care and could be successfully practiced self-care activities by reading guideline, and implement professional recommendations into practice.

In our study, participants those who were housewife less likely to have good self-care practice than those who were not; similar to the finding in India [18]. This might be different reasons, like easily appointed for carrying out the routine household work, probably lack information about self-care practice. An individual who had taken additional medication rather than a single dose of diabetes medication was one of the factors that affect self-care behavior in our study. This was not inline a study conducted in Harari [15]. In our study, taking addition medication might be consequence of drug-drug interactions, medication burden, adverse drug events, and functional decline [25].

Generally, this finding revealed that there were considerable numbers of participants had poor self-care practice (71.6\%). Marital, economical and occupational status, educational level, taking additional medication, treatment modality and social support have a significant factor in order to provide patient own self-care. This 
Table 3 Predictors of self-care behavior among patients with diabetes at FHRH, Northwest Ethiopia, $2016(n=416)$

\begin{tabular}{|c|c|c|c|}
\hline \multirow[t]{2}{*}{ Variable } & $\begin{array}{l}\text { Self-care } \\
\text { practice(n) }\end{array}$ & \multirow[t]{2}{*}{$\operatorname{COR}(95 \% \mathrm{Cl})$} & \multirow[t]{2}{*}{ AOR $(95 \% \mathrm{Cl})$} \\
\hline & Poor Good & & \\
\hline
\end{tabular}

Social support

$\begin{array}{lrrll}\text { Strong } & 38 & 31 & 1 & 1 \\ \text { Moderate } & 97 & 41 & 0.52(0.29,0.94) & 0.50(0.25,1.02) \\ \text { Poor } & 163 & 46 & 0.35(0.19,0.62) & 0.29(0.15,0.59)^{\mathrm{a}}\end{array}$

Educational

Can't read and write $\quad 109 \quad 24 \quad 0.54(0.28,1.02) \quad 1.21(0.46,3.16)$

Read and write $\quad 53 \quad 17 \quad 0.78(0.38,1.60) \quad 1.60(0.61,4.23)$

$\begin{array}{lllll}\text { Primary school } & 41 & 31 & 1.85(0.96,3.57) & 4.82(1.88,12.35)^{\mathrm{a}}\end{array}$

Secondary school $\quad 34 \quad 21 \quad 1.51(0.74,3.08) \quad 3.08(1.26,7.53)^{\mathrm{a}}$

College/University $\quad 61 \quad 25 \quad 1 \quad 1$

Marital status

\section{Widowed}

Divorced

Single

Married

Occupational

Civil servant

Farmer

Private worker

Merchant

House wife

Others $^{\mathrm{b}}$

Income

$\begin{array}{lllll}\text { Very poor } & 73 & 10 & 0.25(0.11,0.56) & 0.27(0.12,0.69)^{a} \\ \text { Poor } & 63 & 23 & 0.66(0.34,1.29) & 0.77(0.36,1.68) \\ \text { Middle } & 58 & 27 & 0.84(0.44,1.62) & 0.96(0.43,2.10) \\ \text { Rich } & 53 & 30 & 1.03(0.54,1.96) & 1.13(0.53,2.42) \\ \text { Very rich } & 51 & 28 & 1 & 1\end{array}$

Taking both oral and insulin

$\begin{array}{lllll}\text { Yes } & 16 & 282 & 2.77(1.33,5.73) & 2.72(1.01,7.40)^{\mathrm{a}} \\ \text { No } & 16 & 102 & 1 & 1\end{array}$

Taking other medication

$\begin{array}{llrll}\text { Yes } & 42 & 256 & 2.37(1.41,3.97) & 2.87(1.43,5.76) \\ \text { No } & 32 & 85 & 1 & 1\end{array}$

a Statically significant; $C O R$ crude odds ratio, $A O R$ adjusted odd ratio

b Retires and students

suggests a health care providers aggressively emphasis on self-care practice by segmenting the patients based on social support, income, treatment regimens and educational status to motivate self-care practice.

\section{Limitation}

Since the data were collected by health professionals working on follow up clinic there might be social desirability bias. The domain of self-care activities were obtained by self-reports and may be limited by recall bias. Another limitation of this study has not addressed whether participants have received any diabetes education or not.

\section{Authors' contributions}

TW initiated the idea, carried out the study, and was involved in drafting and editing the manuscript, and interpretation of the data. MTa contributed edit the proposal, analysis, critically revised the paper, and provided the final version, TMu contributed to the pre-test of the tool; statistical analysis, writing the manuscript, recruit data collectors, and data entry. All authors read and approved the final manuscript.

\section{Author details \\ ${ }^{1}$ Nursing Department, College of Medicine and Health Sciences, Bahir Dar University, P.O.BOX:79, Bahir Dar, Ethiopia. ${ }^{2}$ Psychiatry Department, College of Medicine and Health Sciences, Bahir Dar University, Bahir Dar, Ethiopia. \\ ${ }^{3}$ Nutrition Department, College of Medicine and Health Sciences, Bahir Dar University, Bahir Dar, Ethiopia.}

\section{Acknowledgements}

The authors are grateful to Bahir Dar University for all expenses of the research work, data collectors, and all the study participants who voluntarily participated in this study.

\section{Competing interests}

The authors declare that we have no competing interests.

\section{Availability of data and materials}

The data of this study can't be shared publicly due to the presence of sensitive (confidential) participants' information.

\section{Consent to publish}

Not applicable.

\section{Ethics approval and consent to participate}

In order to follow the ethical and legal standards of scientific investigation, this study was conducted after approval of the proposal by Bahir Dar University institutional review board committee and ethical approval and clearance was obtained from this board. Permission and supportive letter were obtained from respective health bureau and hospital medical director's office before actual data collection. Participation was voluntary and information also was collected anonymously after obtaining written consent from each respondent by assuring confidentiality throughout the data collection period. Participants also were told the objective of the study and gave the right to refuse, stop or withdraw at any time of data collection.

\section{Funding}

The study was funded by the Bahir Dar University. The University was critically reviewed and approved the concept of the study, permitted the study to be conducted, and was involved in data collection process manuscript preparation

\section{Publisher's Note}

Springer Nature remains neutral with regard to jurisdictional claims in published maps and institutional affiliations.

Received: 18 September 2018 Accepted: 22 October 2018

Published online: 08 November 2018

\section{References}

1. American Diabetes Association. Diagnosis and classification of diabetes. Diabetes Care. 2013;36(1):67-74

2. International Diabetes Federation. Global burden of diabetes: how is international diabetes federation facing the challenges? Diabetes atlas. 7th edn; 2015. p. 3-149.

3. Aguirre F, Brown $\mathrm{A}$, Cho NH, Dahlquist $\mathrm{G}$ et al. International diabetes federation. IDF Diabetes Atlas. 6th edn. International Diabetes Federation; 2013. http://www.diabetesatlas.org. 
4. Gizaw M, Harries AD, Ade S, Tayler-Smith K, Ali E, et al. Diabetes mellitus in Addis Ababa, Ethiopia: admissions, complications and outcomes in a large referral hospital. Public Health Action. 2014;1(3):184-8.

5. California Medical Association Foundation. Diabetes care coordination: a team-based quide. CMA Foundation; 2013. p. 1-119.

6. Australian Dietitians Association. The role of credentialled diabetes education and accredited practicing dietitians in the delivery of diabetes self management and nutrition service. Dietitians Assoc. 2015;6(7):5-16.

7. International Diabetes Federation (IDF). Global Diabetes plan 2011-2021. IDF. 2010; 1-28.

8. Nolte Ellen MM. Caring for people with chronic conditions A health system perspective. In: LSE. 2008. p. 25-290.

9. Bridge J, Cabell S, Herring B. Dorothea Orem's Self-Care Deficit Theory. In: Self care deficit theory. 2000. p. 3-24.

10. Guidelines CP. Management of Diabetes Federal Bureau of Prisons clinical practice guidelines. In: Management of Diabetes. 2012. p. 10-50.

11. Selvaraj K, Ramaswamy G, Radhakrishnan S, Thekkur P, Chinnakali P. Selfcare practices among diabetes patients registered in a chronic disease clinic in Puducherry, South India. J Soc Health Diabetes. 2016;4(1):25-9.

12. Arulmozhi S, Mahalakshmy T. Self Care and Medication Adherence among Type 2 Diabetes in Puducherry, Southern India: a Hospital Based Study. J Clin Diagn Res. 2014;8(4):9-11.

13. Berbrayer D. Diabetes and Clinical Research Self-Care among Diabetes Amputee. Int J Diabetes Clin Res. 2015:2(22):2377-3634.

14. Amente T, Belachew THE. Self care practice and its predictor among adults with diabetes mellitus. World J Med Sci. 2014;2(3):1-16.

15. Ayele K, Tesfa B, Abebe L, Tilahun T, Girma E. Self care behavior among patients with diabetes in Harari, Eastern Ethiopia: the health belief model perspective. PLoS ONE. 2012;7(4):e35515
16. Hailu E, Mariam WH, Belachew T, Birhanu Z, Health F, Birhanu Z, et al. Self-care practice and glycemic control amongst adults with diabetes at the Jimma University Specialized Hospital in south-west Ethiopia: a crosssectional study. Afr J Prim Health Care Fam Med. 2012;4(1):1-6.

17. Gopichandran V, Lyndon S, Angel MK, Manayalil BP, Blessy KR, Alex RG, et al. Diabetes self-care activities: a community-based survey in urban southern India. Natl Med J India. 2012;25(1):14-8.

18. Raithatha SJ, Shankar SU, Dinesh K. Self-care practices among diabetes patients in anand District of Gujarat. ISRN Fam Med. 2014;3(1):1-7.

19. Mamo M, Demissie M. Self Care practice and its associated factors among diabetes patients in Addis Ababa public hospitals, cross sectional study. Diabetes Cholest Metabol. 2016;1(4):1-5.

20. Zahra Y, Reza P, Mohammad R, Nastaran A, Leila R, Mohammad Y. Assessment of self-care practice and its associated factors among diabetes patients in urban area of Urmia, Northwest of Iran. JRHS. 2011;11(1):33-8.

21. Gillani SW, Azhar S, Sulaiman S, Baig M, Sari YO, Maisharah S, et al. Diabetes \& metabolism effect of pharmacist intervention to self-care practices among diabetes patients. J Diabetes Metab. 2013;4(3):252-60.

22. Dalgard OS, Bjork S, Tambs K. Social support, negative life events and mental health- a longitudinal study. Br J Psychiatry. 1995;166:29-34.

23. Toobert DJ, Hampson SE, Glasgow RE. The summary of diabetes self-care activities; result from seven studies and a revised scale. Diabetes Care. 2000;23(7):943-50.

24. Ahmann A. Combined therapy in type 2 diabetes mellitus. Drugs Context 2015:4(1):1-7.

25. Fried TR, O'Leary J, Towle V, Goldstein MK, Trentalange M, Martin DK. Health outcomes associated with polypharmacy in community-dwelling older adults: a systematic review. J Am Geriatr Soc. 2014;62(12):2261-72. https://doi.org/10.1111/jgs.13153.
Ready to submit your research? Choose BMC and benefit from:

- fast, convenient online submission

- thorough peer review by experienced researchers in your field

- rapid publication on acceptance

- support for research data, including large and complex data types

- gold Open Access which fosters wider collaboration and increased citations

- maximum visibility for your research: over 100M website views per year

At BMC, research is always in progress.

Learn more biomedcentral.com/submissions 